\title{
Temperature and diet modified swimming behaviors of larval sand dollar
}

\author{
K. Y. K. Chan*, D. Grünbaum \\ School of Oceanography, Box 357940, University of Washington, Seattle, Washington 98195-7940, USA
}

\begin{abstract}
Swimming behaviors of marine invertebrate larvae play key roles in larval dispersal and survival and, hence, have important consequences for adult population dynamics. However, to date, insufficient quantitative information exists on larval swimming to understand and predict swimming movements in most marine invertebrate species. Previous work suggests that larvae swim more slowly at lower temperatures and, consequently, might have difficulty regulating depth when experiencing temperature changes. Improved diet quality in terms of essential fatty acid composition has been suggested to increase cold tolerance in many organisms. We used non-invasive videotracking techniques to quantify swimming in larvae of the sand dollar Dendraster excentricus, raised on 4 algal diets differing in their fatty acid profiles and then exposed to an ecologically relevant temperature decrease from 20 to $12^{\circ} \mathrm{C}$. Differences in diet quality led to significant morphological differences by the 8-arm larval stage, and there were significant diet-temperature interaction effects on swimming patterns. While larval swimming speeds decreased as temperature decreased across all diet treatments, net vertical velocities of larvae did not decrease. Changes in helical geometries of larval swimming trajectories suggest that larvae compensate for reduced swimming speeds by reducing horizontal movement, thus preserving their ability to regulate depth. The observed compensatory mechanism effectively circumvents constraints on swimming due to lowered temperatures. More generally, video-tracking of free-swimming larvae can yield quantitative data to inform biophysically coupled models that better predict consequences of larval dispersal for adult population dynamics under current and future environmental conditions.
\end{abstract}

KEY WORDS: Swimming behaviors · Temperature compensation · Invertebrate larvae · Fatty acids . Dendraster excentricus

Resale or republication not permitted without written consent of the publisher

\section{INTRODUCTION}

The planktonic larvae of marine organisms play important roles in shaping the distribution and abundance of populations. Particularly for organisms with a sessile benthic adult stage, this mobile, transitional phase is the major vehicle for colonizing unoccupied habitats, and for connecting and sustaining existing populations (Cowen et al. 2007, Gaines \& Roughgarden 1985, Underwood \& Fairweather 1989). Biophysically coupled models have been increasingly used to understand and predict larval dispersal patterns due to the challenges of sampling planktonic larvae in the field, and have been used to determine connectivity patterns between disjunct populations and to inform sustainable management strategies (Metaxas \& Saunders 2009).

Recent field and numerical studies have shown that planktonic larvae are not passive drifters for which dispersal outcomes are determined solely by physical mechanisms. Through vertical swimming, larvae can affect the direction and distance they travel by exploiting variations in the strength and direction of advective currents with depth (Dekshenieks et al. 1996, North et al. 2008). In addition to larval transport, swimming behaviors affect larval survival, because other 
environmental characteristics, such as temperature and abundance of predators and food, are also vertically structured (Metaxas 2001).

In spite of its importance, there is to date relatively little quantitative information on larval swimming behavior (Chia et al. 1984, Mileikovsky 1973, Young 1995). Studies of the biomechanics of the ciliary motion of invertebrate larvae have provided estimates of individual swimming capabilities based on ciliary speeds and beating frequencies (e.g. Strathmann 1971, Hart \& Strathmann 1994). Experimental and field studies have demonstrated that invertebrate larvae aggregate along thermoclines and haloclines or in food patches, and avoid water masses with predator cues (Metaxas \& Young 1998, Metaxas et al. 2009, Sameoto \& Metaxas 2008). These observations are revealing populationlevel distributions of larvae. However, these studies do not provide a strong basis for predicting larval distribution in the field, because they do not quantify the underlying behaviors that lead to the observed aggregations. Additional quantitative descriptions of larval swimming behaviors and of how swimming movements change in response to the environmental variability that larvae are likely to encounter would enable us to better parameterize predictive biophysical models (Metaxas 2001).

To provide these quantitative descriptions of larval behavioral responses, we have developed a noninvasive computerized video-tracking technique that enables us to quantify the characteristics of 100s of freely swimming individual larvae in the laboratory at relatively large spatial scales (10s of centimeters) over relatively long periods of time (hours). Similar techniques have been used to study protists (e.g. MenderDeuer \& Grünbaum 2006, Sheng et al. 2007, Mayali et al. 2008) or other larvae (e.g. Fuchs et al. 2004, McDonald 2004, Strathmann \& Grünbaum 2006, Clay \& Grünbaum 2010). Video-tracking is desirable for behavioral studies because it does not require tethering, and allows for relatively large observation chambers in which wall effects are minimal. This approach accurately quantifies specific elements of organism-level movement behaviors, such as turning and reversals between swimming and sinking, that are crucial for predicting long-term water-column distributions.

In the present study, we used video-tracking to quantify responses of larval Dendraster excentricus to variations in temperature and diet quality. D. excentricus is a good model organism for larval swimming studies, because effects of food quantity and quality on its growth and morphology are well characterized (Hart \& Strathmann 1994, Schiopu et al. 2006), effects of low temperature on its ciliary motion have been measured (Podolsky \& Emlet 1993), and effects of larval morphology on its swimming mechanics have been modeled (Grünbaum \& Strathmann 2003, Clay \& Grünbaum 2010).

Temperature and diet are of particular importance to larval behaviors. Sand dollars are found in shallow fjords that experience surface heating and large temperature variations (Emlet 1986). McEdward (1985) showed that electron transport activity in larval sand dollars increases $93 \%$ with a temperature increase from 12 to $22^{\circ} \mathrm{C}$, variability that occurs frequently in sand dollar habitats. Kinematic viscosity of seawater decreases by $\sim 10 \%$ with this $10^{\circ} \mathrm{C}$ increase, implying a greater resistance to swimming at low temperatures (Sleigh \& Blake 1977). Consistent with this, Podolsky \& Emlet (1993) reported that swimming speeds of larval sand dollar were reduced by $40 \%$ when larvae were subjected to this $10^{\circ} \mathrm{C}$ temperature decrease.

Diet, especially food quality in terms of fatty acid profiles, may modulate the behavioral responses of larval Dendraster excentricus to temperature decreases. Fatty acids, particularly long-chain polyunsaturated fatty acids (PUFAs), such as eicosapentaenoic acid [EPA, 20:5(n-3)] and docosahexaenoic acid [DHA, 22:6(n-3)], have been suggested to aid in cold stress tolerance in Daphnia sp. and fish larvae (Brett \& Müller-Navarra 1997, Logue et al. 2000).

With respect to Dendraster excentricus, these earlier studies suggest the hypotheses that larval swimming ability and hence larval survival can be severely affected by temperature decreases commonly experienced in temperate coastal waters, but that sufficiently high diet quality can mitigate or eliminate these deleterious temperature-induced impacts. To test these hypotheses, we raised larval sand dollars on 4 algal diets with different fatty acid profiles. We applied video-tracking techniques to quantify and compare swimming behaviors of larvae from different dietary treatments across an $8^{\circ} \mathrm{C}$ temperature decrease from 20 to $12^{\circ} \mathrm{C}$.

\section{MATERIALS AND METHODS}

Spawning and fertilization. Adult sand dollars Dendraster excentricus were collected from Crescent Beach, East Sound, Orcas Island, Washington, USA, in early summer 2008 and maintained in flow-through sea tables at the Friday Harbor Laboratories until use. Spawning was induced by injecting 0.5 to $1 \mathrm{ml}$ of $0.55 \mathrm{M} \mathrm{KCl}$ into the coelomic cavity (Strathmann 1987). Eggs collected were washed through a $200 \mu \mathrm{m}$ sieve, placed in a beaker with $1000 \mathrm{ml}$ of $<10 \mu \mathrm{m}$ filtered seawater, and fertilized with 5 drops of sperm. Ten minutes after fertilization, the eggs were examined under a microscope for the presence of fertilization envelopes to confirm fertilization success. By fertilizing 
eggs from 3 females with a mixture of sperm from 2 males, 3 maternal lineages were created. Fertilized embryos from different maternal lineages were raised separately. Results from different maternal lineages were later pooled by stage to increase sample size after confirming that their morphology showed no statistical differences (data not shown).

Diet treatments. Larvae were fed 2 species of microalgae, Isochrysis galbana and Dunaliella tertiolecta. The prymnesiophyte $I$. galbana is a common larval food in aquaculture and contains large amounts of EPA and DHA. The chlorophyte D. tertiolecta, a commonly used echinoplutei food, lacks those longchain PUFAs (Tang \& Taal 2005). Other larvae were fed the heterotrophic dinoflagellate Oxyrrhis marina preying on I. galbana or D. tertiolecta. I. galbana and $D$. tertiolecta were cultured in enriched $f / 2$ medium, while $O$. marina $(\sim 50 \mathrm{ml})$ was first inoculated into $200 \mathrm{ml}$ of $I$. galbana or D. tertiolecta culture and later transferred to $1000 \mathrm{ml} \mathrm{f/2}$ medium. All cultures were maintained at $13^{\circ} \mathrm{C}$ on a $14 \mathrm{~h}$ light: $10 \mathrm{~h}$ dark cycle. Heterotrophic protists can 'trophically upgrade' their prey and increase their EPA and DHA content through elongation of shorter chains fatty acids (Klein Breteler et al. 1999). We designated these 4 dietary treatments as Iso, Dun, OxyI, and $O x y D$, respectively.

Larval culture. Larvae were reared under continuous stirring at $16 \pm 1.5^{\circ} \mathrm{C}$ in $600 \mathrm{ml}$ glass jars in $0.45 \mu \mathrm{m}$ filtered seawater at a density of $\sim 2$ ind. $\mathrm{ml}^{-1}$. Each dietary treatment had 4 replicate jars, arranged in a Latin square. Water was changed and food was added every other day. Algal concentration was determined with a hemocytmeter, and biovolumes were estimated according to cell diameter assuming spherical cells. Larvae were fed an equal biovolume of cells (40000, 5000, and 320 cells $\mathrm{ml}^{-1}$ for Iso, Dun, and Oxyrrhis marina culture) to ensure the effect was from food quality and not quantity. In the Iso and Dun treatments, algal cells were centrifuged and the $f / 2$ medium was discarded. Cells were then resuspended in filtered seawater and added to larval cultures. For OxyI and $O x y D$, the cultures were filtered through a $15 \mu \mathrm{m}$ membrane filter to remove algal prey cells, so that only the $O$. marina cells were presented to the larvae.

To assess the effectiveness of the dietary treatments, $25 \mathrm{ml}$ of each algal food and 1000 8-arm larvae were frozen at $-80^{\circ} \mathrm{C}$ for further chemical analyses. Lipids were extracted and analyzed by gas chromatography using the protocol detailed in Ravet et al. (2003). The presence and relative amount of fatty acids detected matched closely with the results published by Tang \& Taal (2005) and Schiopu et al. (2006) (data not shown).

Behavioral observations and video-acquisition. Swimming behaviors of 4 - and 8-arm larvae were quantified at 20 and $12{ }^{\circ} \mathrm{C}$ (a $4^{\circ} \mathrm{C}$ temperature excur- sion in both directions from the rearing temperature of $16^{\circ} \mathrm{C}$ ) in 4 Plexiglas chambers of $3.5 \times 3.5 \times 30 \mathrm{~cm}$, filled with $0.45 \mu \mathrm{m}$ filtered seawater. These 4 chambers were submerged into a common water bath in which temperature was maintained by an immersion circulator (Lauda Ecoline RE-105). This enabled simultaneous observation of larvae from the different dietary treatments. At the beginning of each replicate trial, we pipetted 300 larvae from each treatment into a randomly assigned chamber, and allowed them to acclimate for $30 \mathrm{~min}$. At this density of $<1$ ind. $\mathrm{ml}^{-1}$, interactions between individuals were negligible. Five minutes prior to filming, a Plexiglas stirrer was used to gently re-disperse larvae.

Video clips of larvae were captured at 15 frames $\mathrm{s}^{-1}$ in the dark under infrared illumination, using 2 Panasonic DS400 digital camcorders mounted side by side on a computer-controlled motorized platform such that each camcorder focused on 2 of the 4 chambers without overlap. Video was captured in a series of vertical 'casts' that sequentially imaged lower ( 0 to $14.4 \mathrm{~cm})$ and upper $(11.6$ to $25 \mathrm{~cm})$ regions of the tank. Each cast required $15 \mathrm{~min}$ and consisted of 6 min videos captured in each region of the tank, plus 3 min to reposition cameras. Six casts were performed at the initial temperature of $20^{\circ} \mathrm{C}$. Temperature in the chambers was then lowered to $12^{\circ} \mathrm{C}$ in $2^{\circ} \mathrm{C}$ increments with $30 \mathrm{~min}$ of equilibration time between each increment. Then, 6 casts were performed at $12^{\circ} \mathrm{C}$. Observations were repeated 8 times for each developmental stage.

Larval morphometrics. The 4- and 8-arm larvae were pipetted out of each chamber at the end of each observation and fixed in $90 \%$ sodium bicarbonatebuffered ethanol. Individuals were photographed within $3 \mathrm{wk}$ of preservation under a microscope at $16 \times$ using a Nikon E4500 digital camera. Arm lengths, distances between pairs of arms, body widths, and heights of 10 individuals from each treatment in each observation were measured (total $n=640$ ) with ImageJ (Rasband 2008) and calibrated with photographs of a stage micrometer (Fig. 1).

Video-processing and analysis. Video clips were analyzed by equalizing lighting, removing background variations, selecting moving particles (larvae) based on brightness and size, and extracting the pixel coordinates of larvae in a modified version of the video-editing package avidemux2.4. Videos were calibrated using a grid of $2 \mathrm{~mm}$ squares with $4 \mathrm{~mm}$ spacing. Pixel co-ordinates were converted to physical positions and assembled into larval swimming trajectories by associating points in successive video frames that represented the same organism over time using Tracker3D, an in-house Matlab program (Grünbaum 2009). 


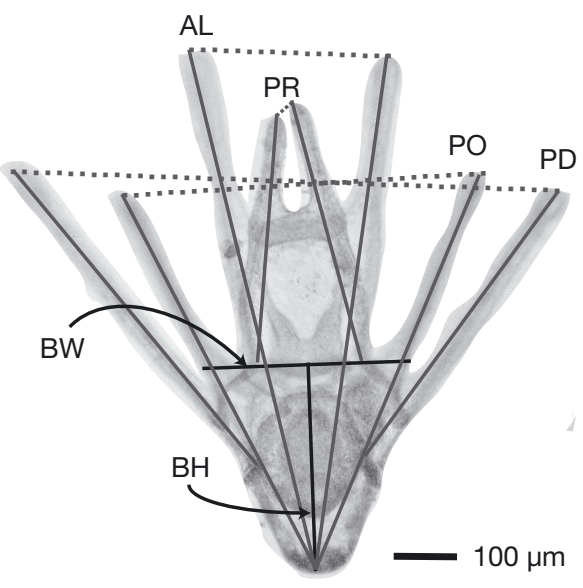

Fig. 1. Dendraster excentricus. Morphometric characteristics of echinopluteus larva. Solid black lines: body width (BW) and height $(\mathrm{BH})$; dark gray lines: lengths of anterolateral arms $(\mathrm{AL})$, postoral arms (PO), preoral arms (PR), and posterodorsal arms (PD); dotted lines: distance between pairs of arms. Note

that PR and PD arm pairs are not present in 4-arm larvae
Statistical analyses. Effects of diet on larval morphometrics were assessed with Kruskal-Wallis tests, as data were not normally distributed. Post hoc Dunn's tests were performed when significant differences were detected ( $\mathrm{p}<0.05$; Zar 1997).

Because larval Dendraster excentricus swim in a helical manner, their trajectories resemble sine waves when viewed as 2-dimensional (2D) projections (Fig. 2a). Only individual trajectories longer than $30 \mathrm{~s}$ that had above-threshold horizontal acceleration $\left(>0.06 \mathrm{~mm} \mathrm{~s}^{-2}\right.$ ) were included in the statistical analyses, to exclude remaining passive particles. We defined the 'path' of a larva using a cubic smoothing spline with short knot spacing, such that the curve followed the actual trajectory while removing frame rate noise (Fig. 2b). We defined the 'axis of travel' analogously, but with long knot spacing such that the resulting curve approximated the overall direction of travel of the trajectory.
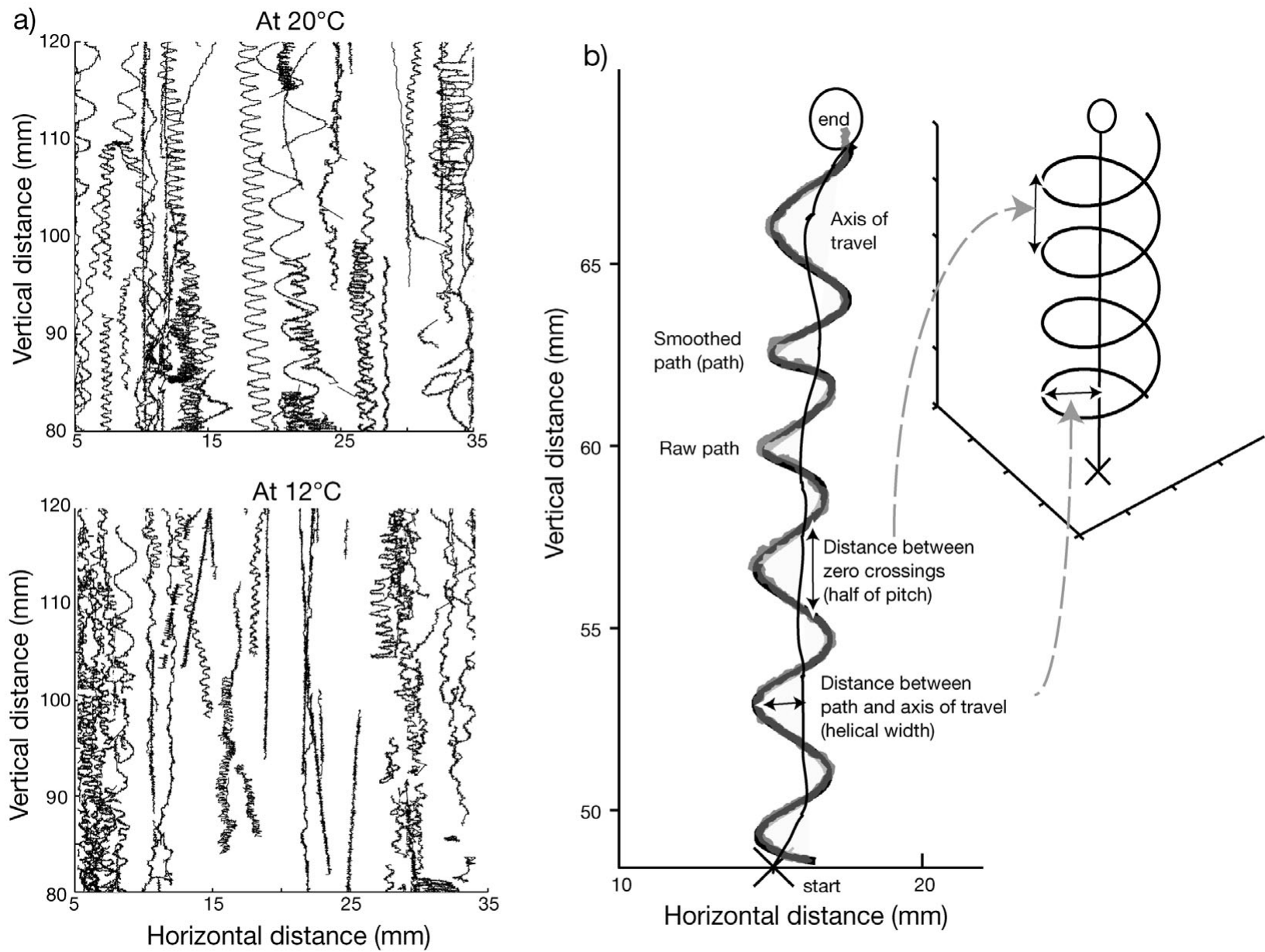

Fig. 2. Dendraster excentricus. (a) Representative larval swimming trajectories at 20 and $12^{\circ} \mathrm{C}$ extracted from 6 min video clips of 4 -arm larvae raised on Dunaliella tertiolecta. Field of view is $30 \times 40 \mathrm{~mm}$. Helical widths were significantly smaller after temperature reduction from 20 to $12^{\circ} \mathrm{C}$. (b) Relationships of swimming metrics to a 3-dimensional helix 
We computed total swimming speed of each path by taking its time derivative. We calculated the net displacement of larvae as the distance between the starting and ending points of the axis of travel. We computed net vertical and horizontal velocities by dividing the net displacement by path duration. We applied a correction factor of $\pi / 2$ to horizontal components to estimate true horizontal velocities from $2 \mathrm{D}$ projections.

We characterized helical larval trajectories using 3 geometric parameters. We defined 'zero crossings' as points at which the path and the axis of travel intersected (Fig. 2b). We computed the oscillatory parameters for trajectories that had at least 5 zero crossings, such that the trajectories had at least 2 complete oscillations. We defined 'oscillatory speed' as the time derivative of the distance between the path and the axis of travel. We also calculated the mean distance between zero crossings, representing the helical pitch, and the maximum distance between the path and the axis of travel, representing helical width.

We computed weighted means of swimming metrics for each vertical cast by sampling at $10 \mathrm{~s}$ time points and averaging trajectories intersecting each time point. This scheme gave equal statistical weight to each frame in which each larva was tracked, avoiding bias towards shorter or longer trajectories.

We performed a principal component analysis (PCA) on the correlation matrix of mean swimming metrics for both 4- and 8-arm larvae with Varimax rotation using Kaiser normalization for data reduction (Harris 1975). We determined the number of factors to retain in further analyses with parallel analysis (PA). We used scores of PCA axes to assess the effect of temperature and diet by comparing the Anderson-Rubin component scores for each treatment using 2-way ANOVA with Bonferroni corrections for each developmental stage. This factorial design consisted of 4 dietary treatments and 2 temperatures, where each treatment had 8 replicates and within each treatment there were 6 representative weighted means for each vertical cast. We performed post hoc Tukey's tests with Bonferroni corrections when significant differences $(p<0.05)$ in component scores were detected (Zar 1997). All statistical analyses were performed in SPSS.

\section{RESULTS}

\section{Larval morphometrics}

There were no significant differences in morphometrics of 4-arm larvae between dietary treatments (Table 1). In contrast, among 8-arm larvae there were significant differences $(\mathrm{p}<0.05)$ between dietary treatments in 8 of the 10 morphometric characteristics. The general trend of morphometric variation was that larvae fed with Dun were largest, followed by larvae fed with Iso, then larvae fed with OxyI, and finally those fed with $O x y D$. Exceptions to this trend were mean lengths of preoral and posterodorsal arms, in which the rank of OxyI and $O x y D$ were reversed (i.e. OxyI had the shortest preoral and posterodoral arms). A post hoc Dunn's test did not yield consistent grouping across morphometric variables.

\section{Principal component analysis}

Loadings of the original variables on PCA Axes 1 to 3 and the percentage of variance these axes explain are listed in Table 2. PCA Axis 1 was heavily loaded with total and oscillatory speeds, with a higher PCA Axis 1

Table 1. Dendraster excentricus. Morphometrics of 4- and 8-arm larvae (mean \pm $\mathrm{SD} ; \mu \mathrm{m})$. Dietary treatments: Dunaliella tertiolecta (Dun), Isochrysis galbana (Iso), Oxyrrhis marina fed with $I$. galbana $(O x y)$, and $O$. marina fed with $D$. tertiolecta $(O x y D)$. Bold: significance by a Kruskal-Wallis test $(\mathrm{p}<0.05)$. Underlining shows groupings based on Dunn's test

\begin{tabular}{|c|c|c|c|c|}
\hline & Dun & Iso & OxyI & $O x y D$ \\
\hline \multicolumn{5}{|l|}{ 4-arm larvae } \\
\hline Body width & $184.3 \pm 2.5$ & $186.6 \pm 2.0$ & $185.3 \pm 2.0$ & $185.7 \pm 1.8$ \\
\hline Body height & $202.3 \pm 1.5$ & $201.5 \pm 2.1$ & $200.8 \pm 1.6$ & $200.5 \pm 1.1$ \\
\hline \multicolumn{5}{|c|}{ Distance between arms } \\
\hline Anterolateral arm & $109.7 \pm 2.7$ & $113.3 \pm 2.8$ & $114.6 \pm 2.7$ & $113.6 \pm 2.8$ \\
\hline Postoral arm & $303.4 \pm 6.1$ & $304.9 \pm 4.4$ & $306.7 \pm 4.5$ & $310.1 \pm 4.4$ \\
\hline \multicolumn{5}{|l|}{ Arm length } \\
\hline Anterolateral arm & $387.9 \pm 4.6$ & $379.0 \pm 4.5$ & $375.2 \pm 5.1$ & $375.5 \pm 5.3$ \\
\hline Postoral arm & $425.1 \pm 4.2$ & $410.9 \pm 5.4$ & $411.9 \pm 5.3$ & $418.1 \pm 5.3$ \\
\hline \multicolumn{5}{|l|}{ 8-arm larvae } \\
\hline Body width & $209.9 \pm 3.3$ & $205.5 \pm 3.5$ & $191.9 \pm 2.7$ & $187.6 \pm 2.2$ \\
\hline Body height & $219.2 \pm 2.1$ & $214.3 \pm 2.0$ & $213.9 \pm 2.4$ & $213.3 \pm 2.1$ \\
\hline \multicolumn{5}{|c|}{ Distance between arms } \\
\hline Anterolateral arm & $\underline{146.6} \pm 3.7$ & $141.7 \pm 2.9$ & $\underline{120.4} \pm 3.5$ & $116.9 \pm 2.3$ \\
\hline Postoral arm & $\underline{376.1} \pm 10.9$ & $353.8 \pm 9.5$ & $319.6 \pm 6.8$ & $300.1 \pm 5.5$ \\
\hline Preoral arm & $51.7 \pm 1.9$ & $47.4 \pm 2.3$ & $\overline{47.5 \pm 1.5}$ & $48.4 \pm 1.4$ \\
\hline Posterodorsal arm & $\underline{522.2} \pm 13.6$ & $580.6 \pm 49.4$ & $400.3 \pm 11.2$ & $352.5 \pm 10.1$ \\
\hline \multicolumn{5}{|l|}{ Arm length } \\
\hline Anterolateral arm & $\underline{458.8} \pm \mathbf{7 . 8}$ & $454.7 \pm 6.8$ & $420.6 \pm 6.3$ & $413.8 \pm 5.5$ \\
\hline Postoral arm & $\underline{443.9 \pm 9.3}$ & $427.6 \pm 8.6$ & $\overline{421.1 \pm 7.4}$ & $406.4 \pm 6.7$ \\
\hline Preoral arm & $192.3 \pm 8.9$ & $181.8 \pm 6.7$ & $115.8 \pm 4.5$ & $131.2 \pm 7.2$ \\
\hline Posterodorsal arm & $310.2 \pm 7.9$ & $314.8 \pm 7.7$ & $214.3 \pm 6.8$ & $238.9 \pm 7.2$ \\
\hline
\end{tabular}



matrix after Varimax rotation with Kaiser normalization was applied. The variables with high loading ( $>0.7$ ) for each component are in bold. Relative variance, cumulative percent, and eigenvalue variance of the correlation are shown for Principal Components (PC) 1 to 3

\begin{tabular}{|lrrr|}
\hline & $\begin{array}{c}\text { PC 1, } \\
\text { speed of } \\
\text { path }\end{array}$ & $\begin{array}{r}\text { PC 2, } \\
\text { helical } \\
\text { width }\end{array}$ & $\begin{array}{r}\text { PC 3, } \\
\text { vertical } \\
\text { velocity } \\
\text { of axis }\end{array}$ \\
\hline Total swimming speed & $\mathbf{0 . 9 6 0}$ & 0.048 & 0.021 \\
Oscillatory speed & $\mathbf{0 . 9 6 0}$ & 0.069 & 0.013 \\
Horizontal velocity of axis of travel & 0.217 & 0.312 & -0.103 \\
Vertical velocity of axis of travel & 0.027 & -0.075 & $\mathbf{0 . 9 9 3}$ \\
Distance between zero crossings & 0.568 & 0.055 & 0.052 \\
Distance between path and axis of travel & 0.065 & $\mathbf{0 . 9 5 6}$ & -0.082 \\
Percent of variance explained & 49.353 & 24.398 & 14.138 \\
Cumulative percent of variance explained & 49.353 & 73.751 & 87.889 \\
Eigenvalue & 2.961 & 1.464 & 0.848 \\
Parallel analysis for principal components & 1.190 & 1.098 & 1.030 \\
\hline
\end{tabular}

Table 2. Principal component and parallel analysis results. Rotated component

\section{Effects of temperature, diet, and their interactions on swimming}

For 4-arm larvae, reducing temperature from 20 to $12^{\circ} \mathrm{C}$ significantly reduced total swimming speeds (PCA Axis 1 scores) across all dietary treatments ( $\mathrm{p}<0.0001$; Table 3, Fig. 3). Helical width (PCA Axis 2 scores) significantly decreased with temperature $(\mathrm{p}<0.0001)$; however, vertical swimming velocities (PCA Axis 3 scores) were not affected by such a decrease $(p=0.994)$. Dietary treatments had no significant effect on any of the 3 PCA axis scores, and there was also no significant temperature-diet interaction effect $(\mathrm{p}>0.3)$.

For 8-arm larvae, reducing the temperature from 20 to $12^{\circ} \mathrm{C}$ significantly score denoting faster total speeds. PCA Axis 2 was heavily loaded with helical width, with a higher PCA Axis 2 score denoting wider helixes. PCA Axis 3 was heavily loaded with vertical swimming velocity, with a higher PCA Axis 3 score denoting faster upward swimming. Parallel analysis (PA) suggested the PCA Axes 1 and 2 be retained because the eigenvalues for these factors were higher than the average eigenvalues for the random factors in PA. This analysis was ambiguous for PCA Axis 3, for which the eigenvalue was close to that of the random factor. We included this PCA axis in further analyses because it is most highly correlated to vertical swimming velocity, which is the most essential variable in controlling larval depth (Table 2). reduced total swimming speeds (PCA Axis 1 scores) across all dietary treatments $(p<0.0001)$. Temperature alone did not have a significant effect on either helical widths (PCA Axis 2 scores, $\mathrm{p}=0.601$ ) or vertical velocities (PCA Axis 3 scores, $\mathrm{p}=0.111$ ). Dietary treatments had a significant effect on helical widths (PCA Axis 2 scores, $\mathrm{p}<0.001$ ), but not on total swimming speeds or vertical velocities. Post hoc tests suggest that larvae raised on $O x y I$ have significantly larger helical widths than those fed on $O x y D$, while there was overlap with the other dietary treatments. There were also significant temperature/diet interaction effects on helical width ( $p=0.047$; Table 3, Fig. 4). This interaction was driven mainly by larvae fed with $O x y I$, in which helical

Table 3. Two-way ANOVA table for the effects of temperature and diet on PCA Axes 1 to 3. The principal component (PC) axes were most significantly affected by speed of path, helical width, and vertical velocity of axis, respectively. Bold: significant difference $(\mathrm{p}<0.05)$

\begin{tabular}{|c|c|c|c|c|c|c|c|c|c|}
\hline & \multirow[t]{2}{*}{ Source } & \multicolumn{4}{|c|}{ - 4-arm larvae- } & \multicolumn{4}{|c|}{ 8-arm larvae - } \\
\hline & & SS & df & $F$ & $\mathrm{p}$ & SS & df & $F$ & $\mathrm{p}$ \\
\hline \multirow[t]{4}{*}{$\begin{array}{l}\text { PC 1, } \\
\text { speed of path }\end{array}$} & Temperature & 18.39 & 1 & 13.31 & $<0.001$ & 12.29 & 1 & 25.54 & $<0.001$ \\
\hline & Diet & 4.30 & 3 & 1.04 & 0.38 & 3.48 & 3 & 2.41 & 0.067 \\
\hline & Temperature $\times$ Diet & 0.91 & 3 & 0.21 & 0.88 & 0.54 & 3 & 0.38 & 0.77 \\
\hline & Error & 446.23 & 323 & - & - & 155.38 & 323 & - & - \\
\hline \multirow{5}{*}{$\begin{array}{l}\text { PC 2, } \\
\text { helical width }\end{array}$} & & & & & & & & & \\
\hline & Temperature & 61.01 & 1 & 74.45 & $<0.001$ & 0.255 & 1 & 0.27 & 0.60 \\
\hline & Diet & 2.26 & 3 & 0.92 & 0.43 & 22.21 & 3 & 7.96 & $<0.001$ \\
\hline & Temperature $\times$ Diet & 2.53 & 3 & 1.03 & 0.38 & 7.49 & 3 & 2.69 & 0.047 \\
\hline & Error & 264.70 & 323 & - & - & 300.53 & 323 & - & - \\
\hline \multirow{4}{*}{$\begin{array}{l}\text { PC } 3 \text {, } \\
\text { vertical velocity } \\
\text { of axis }\end{array}$} & Temperature & $4.81 \times 10^{-5}$ & 1 & 0.000 & 0.994 & 2.63 & 1 & 2.55 & 0.11 \\
\hline & Diet & 2.44 & 3 & 0.88 & 0.45 & 2.92 & 3 & 0.95 & 0.42 \\
\hline & Temperature $\times$ Diet & 3.92 & 3 & 1.42 & 0.24 & 1.97 & 3 & 0.64 & 0.59 \\
\hline & Error & 297.92 & 323 & - & - & 332.92 & 323 & - & - \\
\hline
\end{tabular}




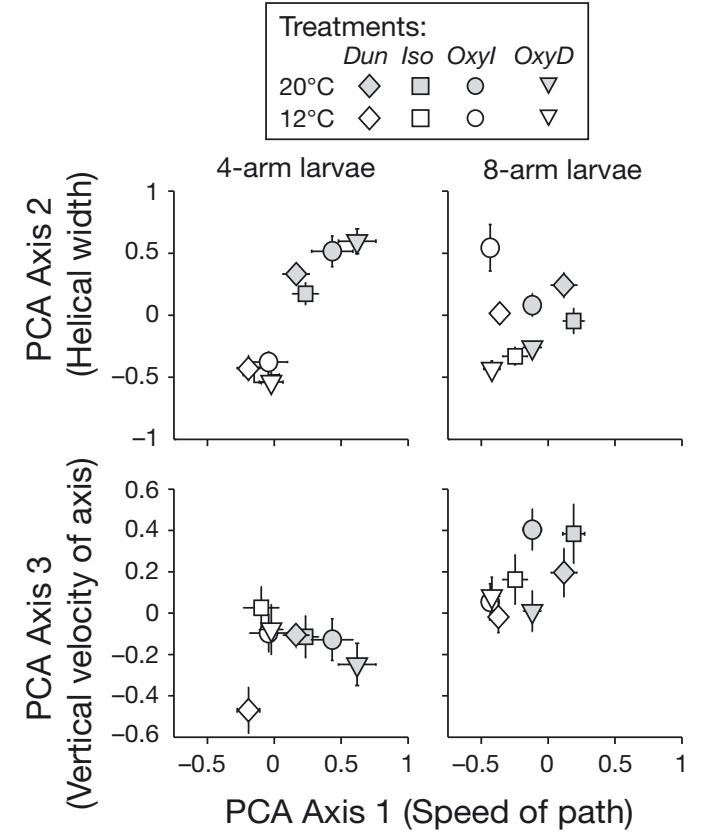

Fig. 3. Dendraster excentricus. Swimming metrics of 4- and 8arm larvae. Treatments as described in Table 1. Open symbols: means of observations at $12^{\circ} \mathrm{C}_{i}$ filled symbols: means of observations at $20^{\circ} \mathrm{C}$. Error bars: SE of means multiplied by 5 width increased with decreasing temperature, while the remaining dietary treatments showed decreased helical widths (Fig. 3).

\section{DISCUSSION}

Swimming behaviors of invertebrate larvae can significantly impact larval survival and dispersal outcomes. Quantitative analysis of larval Dendraster excentricus swimming trajectories showed that swimming capability, as measured by total swimming speed, was compromised when subjected to a significant, environmentally relevant temperature decrease. However, there was a surprising consistency in their upward vertical velocities between temperatures. This suggests a strong compensatory mechanism, which enables larval $D$. excentricus to retain their depth-regulating abilities in spite of reduced swimming capabilities. This compensatory mechanism appears to involve behavioral choices that may effectively circumvent the physiological and biomechanical limitations imposed by low temperature on larval abilities to swim. Diet quality modulated larval responses to decreased temperature.

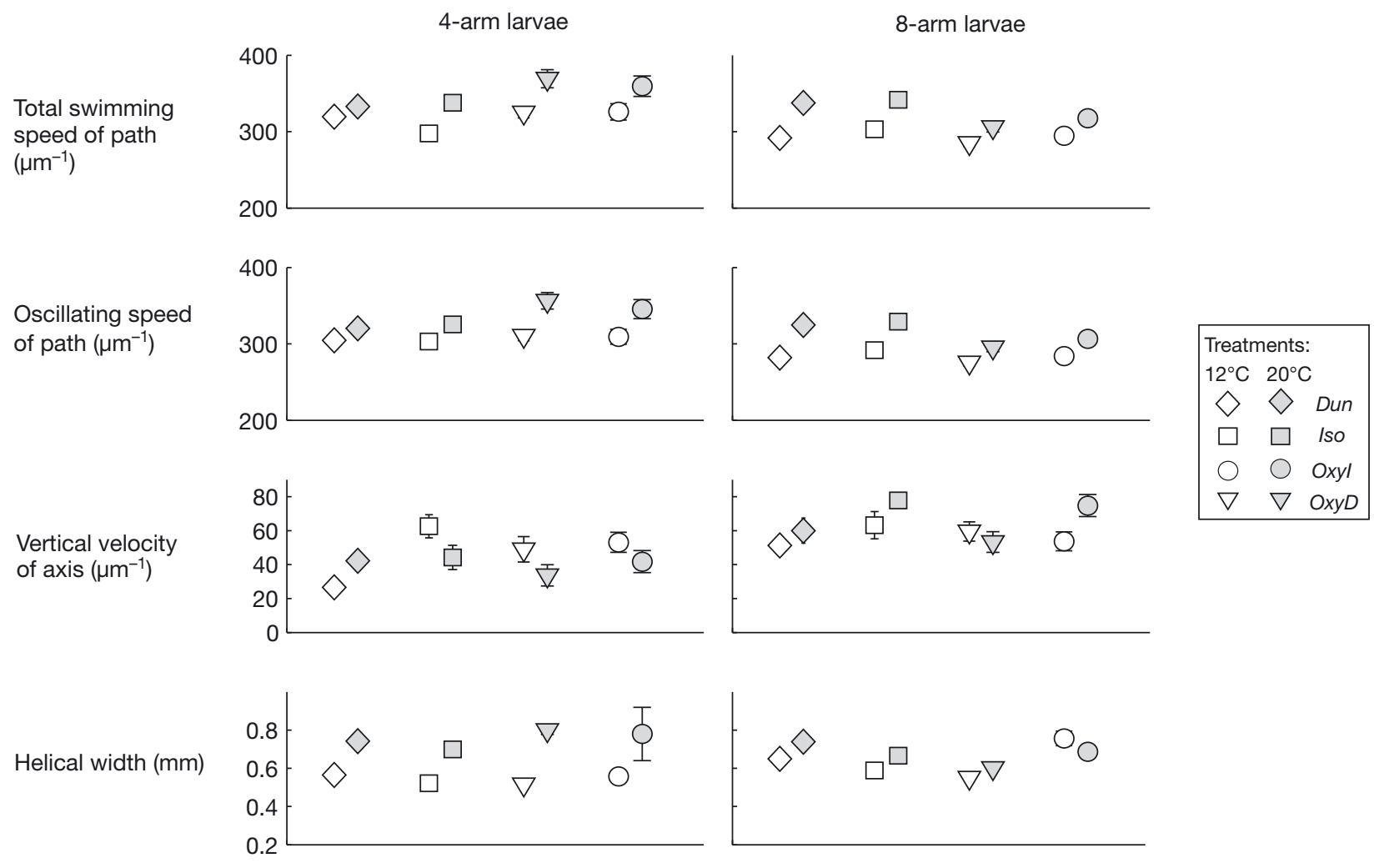

Fig. 4. PCA Axes 2 and 3 scores plotted against PCA Axis 1 scores. Treatments as described in Table 1. Symbols: means of the scores for each dietary treatment. Open symbols: means of observations at $12^{\circ} \mathrm{C}$; filled symbols: means of observations at $20^{\circ} \mathrm{C}$. Error bars: SE of means multiplied by 5 


\section{Temperature compensation in swimming behaviors}

For both 4- and 8-arm larvae, total swimming speed significantly decreased from 20 to $12^{\circ} \mathrm{C}$ (Figs. 3 \& 4). Total swimming speeds of 4 -arm larvae, combining all dietary treatments, dropped from $349.9 \pm 10.3 \mu \mathrm{m} \mathrm{s}^{-1}$ at $20^{\circ} \mathrm{C}$ to $317.2 \pm 7.36 \mu \mathrm{m} \mathrm{s}^{-1}$ at $12^{\circ} \mathrm{C}$. The 8 -arm larvae had a greater between-temperature difference in their total swimming speeds, which dropped from $325.3 \pm$ $6.96 \mu \mathrm{m} \mathrm{s}^{-1}$ at $20^{\circ} \mathrm{C}$ to $293.5 \pm 4.92 \mu \mathrm{m} \mathrm{s}^{-1}$ at $12^{\circ} \mathrm{C}$. These observed total swimming speeds are consistent with a previous prediction, based on physiological and biomechanical constraints, that larvae swim more slowly at lower temperatures (Podolsky \& Emlet 1993). However, in our observations, larval net vertical velocities at both 4- and 8-arm stages were unaffected by the temperature decrease. The 4 -arm larvae had an average net vertical speed of $40.5 \pm 5.63 \mu \mathrm{m} \mathrm{s}^{-1}$ at $20^{\circ} \mathrm{C}$ and $47.5 \pm$ $6.45 \mu \mathrm{m} \mathrm{s}^{-1}$ at $12^{\circ} \mathrm{C}$, whereas 8-arm larvae had an average net vertical speed of $66.0 \pm 7.01 \mu \mathrm{m} \mathrm{s}^{-1}$ at $20^{\circ} \mathrm{C}$ and $56.7 \pm 5.59 \mu \mathrm{m} \mathrm{s}^{-1}$ at $12^{\circ} \mathrm{C}$. Thus, despite the constraints imposed by an $8^{\circ} \mathrm{C}$ temperature decrease, larval Dendraster excentricus maintained their net vertical velocities, implying that their ability to regulate depth through up-swimming was not affected.

The disproportional changes in total and vertical speeds might be explained by the shape of the helical swimming trajectories of larval Dendraster excentricus (Fig. 2a). In both developmental stages, only small portions of larval movements were vertically directed. If the helical geometries of swimming trajectories are behavioral choices rather than fixed physiological or biomechanical properties, larvae may selectively reduce either the horizontal or vertical components of their movement. In that case, changes in total speed would not proportionately translate into changes in net vertical displacement.

In our experiments, larval Dendraster excentricus selectivity reduced the horizontal components of their helical movement so as to minimize the effects of temperature decrease on their vertical movement. Across all dietary treatments, 4-arm larvae swam in narrower helices at $12^{\circ} \mathrm{C}$ than at $20^{\circ} \mathrm{C}$, as evidenced by the decrease in PCA Axis 2 scores. At the 8-arm stage, similar trends were observed in 3 out of 4 dietary treatments, but the differences in helical widths were not statistically significant. It is possible that the changes in helical width for 8-arm larvae were relatively smaller than those of 4 -arm larvae because they had extra lifting force provided by the additional pairs of arms, because their excess densities were reduced by increased lipid storage (Pennington \& Strathmann 1990), or because 8-arm larvae were able to behaviorally adjust their morphologies through the flexing of posterodorsal arms (Burke 1983).
We suggest that maintaining vertical speed and depth-regulating ability through the observed behavioral adjustments is an adaptive response to temperature decreases. Lower temperatures usually reduce larval feeding rates and delay growth (Pechenik 1987). Planktonic mortality rates are often high, especially in cold viscous water where hydrodynamic signals to predators may be magnified and larval escape responses to predator attacks could be compromised (Rumrill 1990, Gallager 1993). Hence, an inability to escape cold water is likely to delay larval development and decrease recruitment success.

The compensatory behavior we observed implies that larval Dendraster excentricus were not maximizing their vertical speeds, at least at the higher temperature we observed, because they did not exercise their abilities to swim in narrower helices. This suggests that intermediate vertical velocities may better satisfy ecological requirements than either slower or faster speeds. However, tradeoffs leading to some advantages for intermediate vertical speeds are at present unclear. Some potential tradeoffs include upswimming to escape cold water masses, maintaining a helical path to limit the exposure volume and thus predation risk (Visser 2007), movement towards phytoplankton-rich surface waters, and avoidance of deleterious UV radiation.

Temperature-dependent changes in helical swimming geometries are not limited to the plutei of sand dollars. Embryos of the red urchin Strongylocentrotus franciscanus swam in helices with higher pitch to slow overall rates of ascent when experiencing a temperature increase from 10 to $14^{\circ} \mathrm{C}$ (McDonald 2004). More generally, many planktonic organisms are known to adjust their helical trajectories, most commonly (as far as is known) in response to food concentration (e.g. Menden-Deuer \& Grünbaum 2006). Our observations suggest that temperature-driven behavioral adjustments, like those found in sand dollar plutei, may be a widespread mechanism among small marine ectotherms to cope with thermal limitations on swimming.

\section{Effects of diet on larval morphologies and swimming behaviors}

For 4-arm larvae, dietary treatments did not affect larval morphologies. This lack of morphological differences is consistent with the findings of Schiopu et al. (2006), who found that significant differences in larval morphologies among dietary treatments started to emerge only $4 \mathrm{~d}$ post-fertilization. This might reflect a time lag during which ingested food is converted into body tissues and maternal reserves are used for growth. Biomechanical modeling studies have sug- 
gested that larval Dendraster excentricus exist in a narrow 'morphospace' such that a slight perturbation to a single morphological parameter could significantly compromise swimming (Grünbaum \& Strathmann 2003, Clay \& Grünbaum 2010). The lack of morphological differences amongst 4-arm larvae from different dietary treatments suggests that swimming metrics should not differ between them, and that expectation is consistent with our observations.

In contrast, morphologies of 8-arm larvae varied significantly between dietary treatments (Table 1). According to the model, larvae with different morphologies are likely to swim differently. However, diet alone did not have a significant effect on either total or net vertical swimming speeds. If the model results are to be believed, this suggests diet-dependent morphological changes in 8-arm larvae were highly coordinated so as to conserve swimming capability as measured by swimming speed.

While all 8-arm larvae were able to maintain their net vertical velocities during the temperature decrease, larvae from 1 of the dietary treatments accomplished this without swimming in narrower helices. Diet and diet/temperature interactions had significant effects on the PCA Axis 2 scores, i.e. helical width (Table 3). Larvae fed Oxyrrhis marina preying on Isochrysis galbana $(O x y I)$ swam in significantly wider helices when temperature was decreased, a trend opposite that seen in the other dietary treatments (Fig. 3). Larvae in the $O x y I$ treatment may have maintained their vertical velocities by increasing helical pitches with decreasing temperature. However, due to the great variability in helical pitch, we were not able to resolve the presence or absence of this potential change in swimming trajectories. Interestingly, OxyI was also the food that had the highest content of EPA, which has been hypothesized to play an important role in cold tolerance (Hall et al. 2002). Further investigations are needed to test whether EPA concentrations could explain why larvae fed OxyIresponded differently to temperature than larvae in the other dietary treatments.

In addition to swimming behaviors, essential fatty acids (PUFAs) may also explain the differences in larval morphologies between dietary treatments. In our experiment, the sizes of 8-arm larvae were negatively correlated to the amount of PUFAs available in the diet (Table 1). This decoupling between PUFAs availability and larval size was hypothesized by George et al. (2008) to be a result of larval Dendraster excentricus desaturating and elongating shorter chain PUFAs into long-chain PUFAs, e.g. steric acid, which are abundant in Dunaliella tertiolecta, into EPA. However, it is also possible that other biochemical differences between dietary treatments (e.g. caloric value, protein, and carbohydrate content) are responsible for the observed dif- ferences in growth and behaviors (Brown et al. 1997). Larvae may also have responded to differences in food quality as they would have to differences in food quantity, by growing longer ciliated arms to increase clearance rates when starved (Hart \& Strathmann 1994).

The observed differences in larval morphologies and responses to temperature changes between dietary treatments have implications for larval transport in the field. In temperate regions, succession in phytoplankton communities corresponds to changes in fatty acid concentrations and compositions of larval food (Hayakawa et al. 1996, Parrish et al. 2005). Spawning seasons of Dendraster excentricus and many other marine organisms span the succession of phytoplankton communities (Strathmann 1987). Larvae released at different times during the spawning season would encounter prey items of different qualities. Our results suggested that dietary treatments had little effect on swimming speeds and that larvae were able to maintain their depth-regulating abilities when temperature changed. An implication of reduced sensitivity to diet and temperature may be less variability in water-column position, and, hence, in longrange larval transport, across long spawning seasons than might otherwise be expected.

Using video-tracking techniques, we obtained detailed quantitative information on larval swimming behaviors and complex responses to environmental conditions that can be used to inform biophysically coupled larval dispersal models. Global climate change is expected to intensify ocean stratification and magnify the temperature changes routinely encountered by small marine ectotherms in estuarine and other marine environments (Cox et al. 2000). Behavioral compensation in helical trajectories suggests marine ectotherms might be better able to regulate their vertical positions in future variable temperature environments than implied by physiology and biomechanics alone.

Acknowledgements. We deeply appreciate the helpful feedback from 3 anonymous reviewers. We thank R. Strathmann for his advice on all aspects of this project, T. Clay for methodological advice, M. Schatz for technical support. We thank Friday Harbor Laboratories and its director K. Sebens. We are grateful for helpful comments on this manuscript from E. Lessard, J. Keister, R. Kiel, and S. Carpenter. This research was supported by a Sir Edward Youde Memorial Fellowship to K.C. and NSF grants OCE-0220284 and NOAA Washington Sea Grant No. NA040AR170032 for D.G.

\section{LITERATURE CITED}

Brett MT, Müller-Navarra DC (1997) The role of highly unsaturated fatty acids in aquatic foodweb processes. Freshw Biol 38:483-499

Brown MR, Jeffrey SW, Volkman JK, Dunstan GA (1997) Nutritional properties of microalgae for mariculture. Aquaculture 151:315-331 
Burke RD (1983) Neural control of metamorphosis in Dendraster excentricus. Biol Bull 164:176-188

Chia FS, Bucklandnicks J, Young CM (1984) Locomotion of marine invertebrate larvae-a review. Can J Zool 62: 1205-1222

Clay TW, Grünbaum D (2010) Morphology-flow interaction led to stage-selective vertical transport of larval sand dollar in shear flow. J Exp Biol 213:1281-1292

Cowen RK, Gawarkiewicz G, Pineda J, Thorrold SR, Werner FE (2007) Population connectivity in marine system: an overview. Oceanography 20:14-21

> Cox PM, Betts RA, Jones CD, Spall SA, Totterdell IJ (2000) Acceleration of global warming due to carbon-cycle feedbacks in a coupled climate model. Nature 408: 184-187

> Dekshenieks MM, Hofmann EE, Klinck JM, Powell EN (1996) Modeling the vertical distribution of oyster larvae in response to environmental conditions. Mar Ecol Prog Ser 136:97-110

Emlet RB (1986) Larval production, dispersal, and growth in a fjord - a case-study on larvae of the sand dollar Dendraster excentricus. Mar Ecol Prog Ser 31:245-254

> Fuchs HL, Mullineaux LS, Solow AR (2004) Sinking behavior of gastropod larvae (Ilyanassa obsoleta) in turbulence. Limnol Oceanogr 49:1937-1949

Gaines S, Roughgarden J (1985) Larval settlement rate-a leading determinant of structure in an ecological community of the marine intertidal zone. Proc Natl Acad Sci USA 82:3707-3711

Gallager SM (1993) Hydrodynamic disturbances produced by small zooplankton-case-study for the veliger larva of a bivalve mollusk. J Plankton Res 15:1277-1296

George SB, Fox C, Wakeham S (2008) Fatty acid composition of larvae of the sand dollar Dendraster excentricus (Echinodermata) might reflect FA composition of the diets. Aquaculture 285:167-173

> Grünbaum D, Strathmann RR (2003) Form, performance and trade-offs in swimming and stability of armed larvae. J Mar Res 61:659-691

Grünbaum D (2009) Tracker3D. Quantifying organism movement: software info \& download. Available at: http://faculty.washington.edu/random/ (accessed on 20 October 2009)

Hall JM, Parrish CC, Thompson RJ (2002) Eicosapentaenoic acid regulates scallop (Placopecten magellanicus) membrane fluidity in response to cold. Biol Bull 202:201-203

Harris RJ (1975) A primer of multivariate statistics. Academic Press, New York, NY

Hart MW, Strathmann RR (1994) Functional consequences of phenotypic plasticity in echinoid larvae. Biol Bull 186: 291-299

> Hayakawa K, Handa N, Kawanobe K, Wong CS (1996) Factors controlling the temporal variation of fatty acids in particulate matter during a phytoplankton bloom in a marine mesocosm. Mar Chem 52:233-244

Klein Breteler WCM, Schogt N, Baas M, Schouten S, Kraay GW (1999) Trophic upgrading of food quality by protozoans enhancing copepod growth: role of essential lipids. Mar Biol 135:191-198

- Logue JA, Howell BR, Bell JG, Cossins AR (2000) Dietary n-3 long-chain polyunsaturated fatty acid deprivation, tissue lipid composition, ex vivo prostaglandin production, and stress tolerance in juvenile Dover sole (Solea solea L.). Lipids 35:745-755

Mayali X, Franks PJS, Tanaka Y, Azam F (2008) Bacteriainduced motility reduction in Lingulodinium polyedrum (Dinophyceae). J Phycol 44:923-928
McDonald K (2004) Patterns in early embryonic motility: effects of size and environmental temperature on vertical velocities of sinking and swimming echinoid blastulae. Biol Bull 207:93-102

> McEdward L (1985) Effects of temperature on the body form, growth, electron transport system echinopluteus. J Exp Mar Biol Ecol 93:169-181

> Menden-Deuer S, Grünbaum D (2006) Individual foraging behaviors and population distributions of a planktonic predator aggregating to phytoplankton thin layers. Limnol Oceanogr 51:109-116

Metaxas A (2001) Behaviour in flow: perspectives on the distribution and dispersion of meroplanktonic larvae in the water column. Can J Fish Aquat Sci 58:86-98

> Metaxas A, Saunders M (2009) Quantifying the 'bio-'components in biophysical models of larval transport in marine benthic invertebrates: advances and pitfalls. Biol Bull 216: $257-272$

Metaxas A, Young CM (1998) Responses of echinoid larvae to food patches of different algal densities. Mar Biol 130: 433-445

> Metaxas A, Mullineaux LS, Sisson J (2009) Distribution of echinoderm larvae relative to the halocline of a salt wedge. Mar Ecol Prog Ser 377:157-168

> Mileikovsky SA (1973) Speed of active movement of pelagic larvae of marine bottom invertebrates and their ability to regulate their vertical position. Mar Biol 23:11-17

North EW, Schlag Z, Hood RR, Li M, Zhong L, Gross T, Kennedy VS (2008) Vertical swimming behavior influences the dispersal of simulated oyster larvae in a coupled particle-tracking and hydrodynamic model of Chesapeake Bay. Mar Ecol Prog Ser 359:99-115

Parrish CC, Thompson RJ, Deibel D (2005) Lipid classes and fatty acids in plankton and settling matter during the spring bloom in a cold ocean coastal environment. Mar Ecol Prog Ser 286:57-68

Pechenik JA (1987) Environmental influences on larval survival and development. In: Giese A, Pearse J, Pearse V (eds) Reproduction of marine invertebrates, Vol X. Blackwell Scientific, Palo Alto, CA, p 511-608

> Pennington JT, Strathmann RR (1990) Consequences of the calcite skeletons of planktonic echinoderm larvae for orientation, swimming, and shape. Biol Bull 179:121-133

Podolsky RD, Emlet RB (1993) Separating the effects of temperature and viscosity on swimming and water movement by sand dollar larvae (Dendraster excentricus). J Exp Biol $176: 207-222$

Rasband WS (2008) ImageJ. US National Institutes of Health, Bethesda, MD. Available at: http://rsb.info.nih.gov/ij/

Ravet JL, Brett MT, Müller-Navarra DC (2003) A test of the role of polyunsaturated fatty acids in phytoplankton food quality for Daphnia using liposome supplementation. Limnol Oceanogr 48:1938-1947

Rumrill SS (1990) Natural mortality of marine invertebrate larvae. Ophelia 32:163-198

Sameoto JA, Metaxas A (2008) Can salinity-induced mortality explain larval vertical distribution with respect to a halocline? Biol Bull 214:329-338

Schiopu D, George SB, Castell J (2006) Ingestion rates and dietary lipids affect growth and fatty acid composition of Dendraster excentricus larvae. J Exp Mar Biol Ecol 328:47-75

Sheng J, Malkiel E, Katz J, Adolf J, Belas R, Place AR (2007) Digital holographic microscopy reveals prey-induced changes in swimming behavior of predatory dinoflagellates. Proc Natl Acad Sci USA 104:17512-17517

Sleigh MA, Blake JR (1977) Methods of ciliary propulsion and 
their size limitations. In: Pedley TJ (ed) Scale effects in animal locomotion. Academic Press, London, p 243-256

Strathmann RR (1971) The feeding behavior of planktotrophic echinoderm larvae: mechanisms, regulation, and rates of suspension feeding. J Exp Mar Biol Ecol 6:109-160

Strathmann MF (1987) Reproduction and development of the northern coast. The University of Washington Press, Seattle, WA

Strathmann RR, Grünbaum D (2006) Good eaters, poor swimmers: compromises in larval form. Integr Comp Biol 46: 312-322

Tang KW, Taal M (2005) Trophic modification of food quality

Editorial responsibility: Steven Morgan,

Bodega Bay, California, USA by heterotrophic protists: species-specific effects on copepod egg production and egg hatching. J Exp Mar Biol Ecol 318:85-98

Underwood AJ, Fairweather PG (1989) Supply-side ecology and benthic marine assemblages. Trends Ecol Evol 4: $16-20$

Visser AW (2007) Motility of zooplankton: fitness, foraging and predation. J Plankton Res 29:447-461

Young CM (1995) Behavior and locomotion during the dispersal phase of larval life. In: McEdward L (ed) Ecology of marine invertebrate larvae. CRC Press, Boca Raton, FL

Zar JH 1997. Biostatistical analysis. Prentice-Hall, London

Submitted: February 4, 2010; Accepted: July 20, 2010

Proofs received from author(s): September 13, 2010 